Note

\title{
Simultaneous Determination of Seven Kinds of Fungicides in Citrus Fruits by Gas Chromatograghy/Mass Spectrometry
}

\author{
Hideo Nagashima*, Akiho Hirao, Yuuki ToKuda and Kumiko Uruta \\ Setagaya Public Health Center: 1-11-18 MK-Earth Building, Setagaya, Setagaya-ku, Tokyo 154-0017, Japan; \\ ${ }^{*}$ Corresponding author
}

\begin{abstract}
A simple and accurate procedure was developed for the determination of seven fungicides, azoxystrobin (AZO), diphenyl (DP), fludioxonil (FLUDI), imazalil (IMZ), o-phenylphenol (OPP), pyrimethanil (PYRI) and thiabendazole (TBZ), in citrus fruits. The citrus fruit sample was extracted with acetonitrile and cleaned up with a graphite carbon/aminopropyl silanized silica gel solid-phase extraction cartridge using acetonitrile-toluene $(3: 1, \mathrm{v} / \mathrm{v})$ as the eluent. Triphenylene was used as an internal standard (I.S.) at the concentration of $0.5 \mu \mathrm{g} / \mathrm{mL}$. The sample solution was subjected to GC-MS utilizing the matrix-matched standard solution method. The recoveries of AZO, FLUDI, IMZ, OPP, PYRI and TBZ spiked in domestic citrus fruits (Satsuma mandarin) at the level of 0.01$10.0 \mu \mathrm{g} / \mathrm{g}$ were $72.8-104 \%$ and the limits of quantification were $0.01 \mu \mathrm{g} / \mathrm{g}$. The recoveries of DP spiked in domestic citrus fruits at the level of $0.01-70.0 \mu \mathrm{g} / \mathrm{g}$ were $70.8-80.4 \%$ and the limit of quantification was $0.01 \mu \mathrm{g} / \mathrm{g}$. The proposed method was applied to the determination of fungicides in citrus fruits purchased in various markets.
\end{abstract}

(Received December 22, 2015)

Key words: fungicide; citrus fruit; chromatograghy/mass spectrometry

\section{Introduction}

Various fungicides are permitted for use on citrus fruits and some other fruits in Japan. The levels of fungicides used in these fruits are regulated by the Food Sanitation Law. FLUDI was newly permitted in 2011, and AZO and PYRI were also approved in 2013 by the Ministry of Health, Labour and Welfare of Japan. The antifungal agents AZO, DP, FLUDI, IMZ, OPP, PYRI and $\mathrm{TBZ}^{1,2)}$ belong to different chemical classses and are contained mainly in imported citrus fruits. These chemical structures are shown in Fig. 1.

Although Yoshioka et $a l^{3)}$ recently reported determination methods for AZO, FLUDI, IMZ, PYRI and TBZ by LC-MS and for DP and OPP by HPLC, a GC-MS method could monitor all seven fungicides in a single run. Therefore, we developed a GC-MS method for simultaneous identification and quantification of these fungicides and confirmed its suitability for the determination of the fungicides in citrus fruits.

\section{Materials and Methods}

\section{Chemicals and reagents}

Acetonitrile, acetone, ethyl acetate, hexane and toluene used throughout the procedure were of pesticide residue analysis grade. Anhydrous sodium sulfate and sodium chloride were also of pesticide residue analysis grade, and dipotassium hydrogenphosphate, potassium

*sea02013@mb.city.setagaya.tokyo.jp dihydrogen phosphate, triphenylene, fluorene were of reagent grade, purchased from Kanto Chemical Co., Inc. (Tokyo, Japan). Anthracene (standard material 99.5\% min) was purchased from Wako Pure Chemical Industries, Ltd. (Osaka, Japan). Milli-Q grade water was also used. The phosphate buffer solution ( $\mathrm{pH}$ 7.0) was prepared as follows: $52.7 \mathrm{~g}$ of dipotassium hydrogen phosphate and $30.2 \mathrm{~g}$ of potassium dihydrogen phosphate were dissolved in $500 \mathrm{~mL}$ of water, the $\mathrm{pH}$ was adjusted to 7.0 with $1 \mathrm{~mol} / \mathrm{L}$ sodium hydroxide solution, and the volume of the buffer solution was made up to $1,000 \mathrm{~mL}$ with water.

Imazalil (IMZ) (reference material for residue analysis 99.0\%) and pyrimethanil (PYRI) (reference material for residue analysis 99.0\%) were obtained from Dr. Ehrenstorfer GmbH (Augsburg, Germany), diphenyl (DP) (biphenyl for pesticide residue analysis 99\% $\mathrm{min}$ ), ophenylphenol (OPP) (2-phenylphenol for pesticide residue analysis $99 \% \mathrm{~min}$ ), thiabendazole (TBZ) (for pesticide residue analysis 99\% $\mathrm{min}$ ) and fludioxonil (FLUDI) (for pesticide residue analysis 99\% min) were from Kanto Chemical Co., Inc. and azoxystrobin (AZO) (traceable reference material $99.6 \%$ min) was from Wako Pure Chemical Industries, Ltd. The solid-phase extraction cartridges were ENVI-Carb/LC-NH2 (6 mL tube, $500 \mathrm{mg} / 500 \mathrm{mg}$ ), purchased from SUPELCO (Bellefonte, USA), and InertSep GC/PSA (500 mg/500 mg/6 mL), purchased from GL Sciences Inc. (Tokyo, Japan). Filter paper $(5 \mathrm{~A}$, diameter $11 \mathrm{~cm})$ was purchased from TOYO Roshi Co., Ltd. (Tokyo, Japan). 


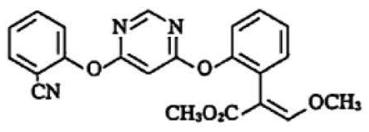

Azoxystrobin (AZO)

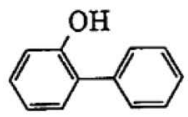

o-Phenylphenol (OPP)

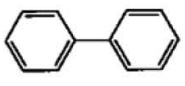

Diphenyl (DP)

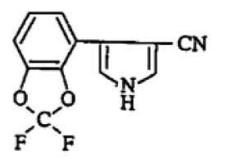

Fludioxonil (FLUDI)<smiles>C=CCOC(=O)c1ccc(Cl)cc1</smiles>

Imazalil (IMZ)

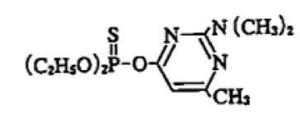

Pyrimethanil (PYRI)
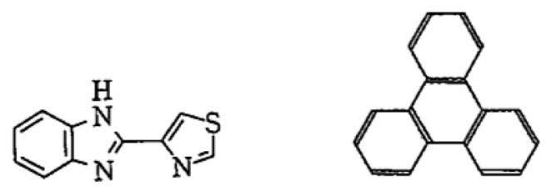

Fig. 1. Chemical structures of the fungicides examined and the I.S.

Standard stock solutions of fungicides $(500 \mu \mathrm{g} / \mathrm{mL})$ : $0.0100 \mathrm{~g}$ of each fungicide was taken into a $20 \mathrm{~mL}$ volumetric flask and dissolved in acetone. Internal standard (I.S.) stock solution of triphenylene $(500 \mu \mathrm{g} / \mathrm{mL})$ : $0.0100 \mathrm{~g}$ of triphenylene was taken into a $20 \mathrm{~mL}$ volumetric flask and dissolved in acetone. A mixed solution of seven fungicides was prepared at the concentration of $20 \mu \mathrm{g} / \mathrm{mL}$, and an I.S. solution of triphenylene at the concentration of $10 \mu \mathrm{g} / \mathrm{mL}$ was also prepared. The mixed standard stock solution was diluted to prepare mixed standard solutions for calibration curves in the range of $0.1-2.0 \mu \mathrm{g} / \mathrm{mL}$ for AZO, DP, FLUDI, IMZ, OPP, PYRI and TBZ. Triphenylene was added at the concentration of $0.5 \mu \mathrm{g} / \mathrm{mL}$. Matrix solution not containing fungicides, prepared in advance from domestic citrus fruits (Satsuma mandarin), was also added at a quantity of more than a quarter of the diluted standard solutions at the final phase of making up the volume with acetone.

\section{Samples}

Lemon, orange, grapefruit, Satsuma mandarin and other citrus fruits were purchased from markets in Tokyo.

\section{Sample preparation}

More than $1.0 \mathrm{~kg}$ of a sample was homogenized with a food processor (Cuisinart DLC-10 purchased from Conair Japan G.K., Tokyo, Japan). The following sample solution preparation method is almost the same as Multi-residue Method I for agricultural chemicals by GC-MS (Shoku-An No. 1129002, 29th November, 2005). A $20.0 \mathrm{~g}$ aliquot of the sample was taken into a $200 \mathrm{~mL}$ homogenizer cup, $100 \mathrm{~mL}$ of acetonitrile was added, and the mixture was homogenized for $5 \mathrm{~min}$ (10,000 rpm) using a homogenizer (Excel Auto Homogenizer Model ED purchased from Nihonseiki Kaisha Ltd., Tokyo, Japan). The supernatant was taken and then $100 \mathrm{~mL}$ of acetonitrile was added to the residue, which was again homogenized. The combined supernatant was filtered through filter paper (5A) and $80 \mathrm{~mL}$ of phosphate buffer solution ( $\mathrm{pH} 7.0$ ) and $40 \mathrm{~g}$ of sodium chloride were added. The mixture was shaken for $10 \mathrm{~min}$. The organic solvent phase was taken and dried with $40 \mathrm{~g}$ of anhydrous sodium sulfate, and the supernatant was filtered through filter paper (5A). The filtrate was concentrated under reduced pressure and dried with nitrogen gas. The residue was dissolved in $10 \mathrm{~mL}$ of acetonitrile-toluene $(3: 1$, v/ v). The solution was loaded onto an ENVI-Carb/LC-NH2 solid-phase extraction cartridge, previously conditioned with $10 \mathrm{~mL}$ of acetonitrile-toluene $(3: 1, \mathrm{v} / \mathrm{v})$, and eluted with $20 \mathrm{~mL}$ of acetonitrile-toluene $(3: 1, \mathrm{v} / \mathrm{v})$. The eluate was concentrated under reduced pressure and dried with nitrogen gas. The residue was dissolved in $2 \mathrm{~mL}$ of acetone containing $0.5 \mu \mathrm{g} / \mathrm{mL}$ triphenylene as an I.S. If it was necessary to dilute the sample solution, the concentration of triphenylene was adjusted to $0.5 \mu \mathrm{g} / \mathrm{mL}$ with $10 \mu \mathrm{g} / \mathrm{mL}$ internal standard solution of triphenylene, and the matrix solution not containing fungicides (prepared in advance from domestic citrus fruits) was also added at a quantity of more than a quarter of the diluted sample solution at the final phase of making up the volume with acetone.

\section{GC-MS instrument conditions}

The fungicides were determined by GC-MS with electron impact mass spectrometric detection at $70 \mathrm{eV}$. The GC-MS system was a Jms-Q 1000 GCMK II (JEOL, Tokyo, Japan). A fused silica capillary column DB-5MS+ DB $(0.25 \mathrm{~mm}$ i.d., length $30 \mathrm{~m}$, film thickness $0.25 \mu \mathrm{m}$ Agilent Technologies Inc., USA) was employed. Operating conditions were as follows: injection port temperature $260^{\circ} \mathrm{C}$; oven temperature was programmed to $50^{\circ} \mathrm{C}$ $(1 \mathrm{~min}) \rightarrow 10^{\circ} \mathrm{C} / \mathrm{min} \rightarrow 180^{\circ} \mathrm{C}(0 \mathrm{~min}) \rightarrow 5^{\circ} \mathrm{C} / \mathrm{min} \rightarrow 300^{\circ} \mathrm{C}$ (10 min); carrier gas, helium; flow rate $1.0 \mathrm{~mL} / \mathrm{min}$; temperature of ion source $270^{\circ} \mathrm{C}$; temperature of interface $280^{\circ} \mathrm{C}$; sample size $2 \mu \mathrm{L}$; splitless injection. The retention times and $m / z$ values for the determination of fungicides are shown in Table 1. 
Table 1. Retention times and $m / z$ values of fungicides

\begin{tabular}{lcccc}
\hline \hline \multirow{2}{*}{ Compound } & \multicolumn{2}{l}{$\begin{array}{l}\text { Retention } \\
\text { time }\end{array}$} & \multicolumn{3}{c}{$m / z$} \\
\cline { 2 - 6 } & (min : sec) & Quantitative & Confirmative \\
\hline Diphenyl (DP) & $12: 26$ & 154 & 153 & \\
o-Phenylphenol (OPP) & $14: 12$ & 170 & 169 & 141 \\
Pyrimethanil & $18: 05$ & 198 & 199 & \\
(PYRI) & & & & \\
Thiabendazole (TBZ) & $22: 34$ & 201 & 174 & \\
Imazalil (IMZ) & $23: 54$ & 215 & 173 & \\
Fludiozonil (FLUDI) & $23: 58$ & 248 & 127 & 154 \\
Azoxystrobin (AZO) & $37: 22$ & 344 & 388 & \\
Triphenylene & $28: 25$ & 228 & 113 & \\
\hline
\end{tabular}

Triphenylene: Internal standard

\section{Results and Discussion}

\section{1. $G C-M S$}

Yoshioka et $a l .^{3)}$ reported that the sensitivities for DP and OPP were low on LC-MS (ESI) analysis, so they determined these two fungicides by HPLC equipped with a fluorescence detector, while AZO, FLUDI, IMZ, PYRI and TBZ were analysed by LC-MS. However, the sensitivities for AZO and FLUDI also seemed to be insufficient for application in real matrices. Generally speaking, the theoretical plate number of a GC capillary column is greater than that of an HPLC analytical column. Thus, GC-MS chromatograms show better resolution, selectivity and sensitivity than HPLC chromatograms for determination of fungicides. Therefore, a GCMS method should be able to monitor all seven fungicides simultaneously in one run.

Although the oven temperature program for GC-MS for pesticide residue analysis is usually begun from $80^{\circ} \mathrm{C}$ and gradually increased at the rate of $15^{\circ} \mathrm{C} / \mathrm{min}$ to $180^{\circ} \mathrm{C}$, for the present purpose, the initial temperature was set at $50^{\circ} \mathrm{C}$ and gradually increased at the rate of $10^{\circ} \mathrm{C} / \mathrm{min}$ to $180^{\circ} \mathrm{C}$. Under these conditions, DP and OPP were determined without any interfering peak.

\section{Extraction solvent and liquid-liquid partition}

Acetonitrile, acetone and ethyl acetate are usually used as extraction solvents for the determination of pesticides. These solvents were examined as extraction solvents for the determination of fungicides in citrus fruits. Although the extracted solution for pesticide residue analysis is usually filtered through a diatomaceous earth layer, PYRI was absorbed on diatomaceous earth. Therefore the extracted solution could not be filtered through a diatomaceous earth layer for simultaneous determination of fungicides.

The seven fungicides were spiked in domestic citrus fruits (Satsuma mandarin) at the level of $1.0 \mu \mathrm{g} / \mathrm{g}$, and the results of extraction with acetonitrile, acetone and ethyl acetate were compared. As shown in Table 2, extraction with acetonitrile gave the best recoveries, so acetonitrile was selected as the extraction solvent for the determination of fungicides.
Table 2. Comparison of extraction solvents

\begin{tabular}{lccccccc}
\hline \hline \multirow{2}{*}{$\begin{array}{l}\text { Extraction } \\
\text { solvent }\end{array}$} & \multicolumn{6}{c}{ Spiked level $(1.0 \mu \mathrm{g} / \mathrm{g})$} \\
\cline { 2 - 8 } & AZO & DP & FLUDI & IMZ & OPP & PYRI & TBZ \\
\hline \multirow{2}{*}{ Acetonitrile } & 92.2 & 92.2 & 92.7 & 82.1 & 99.4 & 95.2 & 90.8 \\
& $(3.1)$ & $(3.5)$ & $(1.9)$ & $(0.5)$ & $(0.4)$ & $(2.7)$ & $(2.4)$ \\
Acetone & 85.2 & 82.7 & 88.3 & 86.8 & 97.8 & 92.7 & 89.2 \\
& $(2.0)$ & $(1.0)$ & $(0.5)$ & $(0.6)$ & $(1.1)$ & $(1.5)$ & $(1.2)$ \\
Ethyl acetate & 81.7 & 79.0 & 76.1 & 85.7 & 96.3 & 95.5 & 91.3 \\
& $(2.9)$ & $(3.7)$ & $(1.3)$ & $(3.7)$ & $(2.3)$ & $(1.8)$ & $(2.4)$ \\
\hline
\end{tabular}

Table 3. Comparison of $\mathrm{pH}$ for phosphate buffer solution

\begin{tabular}{|c|c|c|c|c|c|c|c|}
\hline \multirow{3}{*}{$\begin{array}{l}\text { pH for } \\
\text { phosphate } \\
\text { buffer } \\
\text { soln. }\end{array}$} & \multicolumn{7}{|c|}{ Spiked level $(1.0 \mu \mathrm{g} / \mathrm{g})$} \\
\hline & \multicolumn{7}{|c|}{ Recovery (\%) (RSD (\%)) $n=3$} \\
\hline & $\mathrm{AZO}$ & DP & FLUDI & $\mathrm{IMZ}$ & $\mathrm{OPP}$ & PYRI & TBZ \\
\hline \multirow[t]{2}{*}{4.0} & 86.4 & 90.3 & 92.8 & 85.0 & 99.2 & 97.2 & 7.8 \\
\hline & (3.3) & $(0.1)$ & (4.1) & (4.3) & $(4.3)$ & $(5.4)$ & $(0.6)$ \\
\hline \multirow[t]{2}{*}{7.0} & 92.2 & 92.2 & 92.7 & 82.1 & 99.4 & 95.2 & 90.8 \\
\hline & (3.1) & (3.5) & (1.9) & $(0.5)$ & $(0.4)$ & $(2.7)$ & $(2.4)$ \\
\hline \multirow[t]{2}{*}{10.0} & 92.1 & 89.0 & 90.9 & 81.2 & 99.9 & 98.9 & 91.7 \\
\hline & $(0.3)$ & (1.0) & (1.2) & (1.5) & (1.6) & $(1.2)$ & (1.1) \\
\hline
\end{tabular}

\section{The $p H$ value of the phosphate buffer solution}

We examined phosphate buffer solution of $\mathrm{pH}$ 4.0, 7.0 and 10.0 for washing the extracted solution. The phosphate buffer solution ( $\mathrm{pH} 4.0)$ and the phosphate buffer solution ( $\mathrm{pH} 10.0$ ) were prepared using $0.5 \mathrm{~mol} / \mathrm{L}$ potassium dihydrogenphosphate solution and $0.5 \mathrm{~mol} / \mathrm{L}$ dipotassium hydrogenphosphate solution, respectively, and the $\mathrm{pH}$ was adjusted to 4.0 with $1 \mathrm{~mol} / \mathrm{L} \mathrm{HCl}$ solution and 10.0 with $1 \mathrm{~mol} / \mathrm{L} \mathrm{NaOH}$ solution, respectively. The fungicides were spiked at the level of $1.0 \mu \mathrm{g} / \mathrm{g}$ in Satsuma mandarin. The analytical results are shown in Table 3.

Although almost the same results were obtained at pH 7.0 and 10.0, the recovery of TBZ was low at pH 4.0. Therefore, phosphate buffer solution ( $\mathrm{pH}$ 7.0) was selected for the determination of the fungicides.

\section{Solid-phase extraction cartridges}

Pesticides in agricultural products were extracted with acetonitrile, then enriched and cleaned up with solid-phase extraction (SPE) cartridges using acetonitriletoluene $(3: 1, \mathrm{v} / \mathrm{v})$ as the eluent. Not only graphite carbon/aminopropyl silanized silica gel (GC/NH2), but also graphite carbon/primary secondary amino silanized silica gel (GC/PSA) are usually used as cartridges for the determination of pesticides. ENVI-Carb/LC-NH2 as a GC/NH2 cartridge and InertSep GC/PSA as a GC/PSA cartridge were investigated in this study. As the eluent, acetonitrile-toluene $(3: 1, \mathrm{v} / \mathrm{v})$ solution was used. The fungicides were spiked at the level of $1.0 \mu \mathrm{g} / \mathrm{g}$ in Satsuma mandarin. The analytical results are shown in Table 4. ENVI-Carb/LC-NH2 gave better analytical results than InertSep GC/PSA. 
Table 4. Comparison of SPE cartridges

\begin{tabular}{cccccccc}
\hline \hline \multirow{2}{*}{ SPE } & \multicolumn{6}{c}{ Spiked level $(1.0 \mu \mathrm{g} / \mathrm{g})$} \\
\cline { 2 - 8 } & AZO & DP & FLUDI & IMZ & OPP & PYRI & TBZ \\
\cline { 2 - 8 } & & & & \\
ENVI-Carb/ & 92.2 & 92.2 & 92.7 & 82.1 & 99.4 & 95.2 & 90.8 \\
LC-NH2 & $(3.1)$ & $(3.5)$ & $(1.9)$ & $(0.5)$ & $(0.4)$ & $(2.7)$ & $(2.4)$ \\
InertSep GC/ & 90.9 & 90.2 & 92.7 & 78.5 & 98.9 & 99.3 & 83.2 \\
PSA & $(3.4)$ & $(4.9)$ & $(1.7)$ & $(5.7)$ & $(3.2)$ & $(2.4)$ & $(3.2)$ \\
\hline
\end{tabular}

Table 5. Comparison of standard solutions which contain matrix solution or not

\begin{tabular}{|c|c|c|c|c|c|c|}
\hline \multirow{3}{*}{$\begin{array}{c}\text { Spiked } \\
\text { level } \\
(\mu \mathrm{g} / \mathrm{g})\end{array}$} & \multicolumn{6}{|c|}{ Recovery (\%) (RSD (\%)) $n=5$} \\
\hline & \multicolumn{2}{|c|}{ DP } & \multicolumn{2}{|c|}{ OPP } & \multicolumn{2}{|c|}{ PYRI } \\
\hline & Matrix & $\begin{array}{c}\text { No } \\
\text { matrix }\end{array}$ & Matrix & $\begin{array}{c}\text { No } \\
\text { matrix }\end{array}$ & Matrix & $\begin{array}{c}\text { No } \\
\text { matrix }\end{array}$ \\
\hline \multirow[t]{2}{*}{0.01} & 98.8 & 219 & 104 & 138 & 89.0 & 106 \\
\hline & (1.9) & (1.7) & (8.3) & $(7.2)$ & $(0.9)$ & (0.8) \\
\hline \multirow[t]{2}{*}{0.10} & 79.4 & 175 & 90.6 & 101 & 85.0 & 86.3 \\
\hline & (4.1) & $(2.2)$ & (7.4) & (5.6) & $(4.7)$ & (1.7) \\
\hline \multirow[t]{2}{*}{1.0} & 80.4 & 188 & 89.8 & 107 & 90.6 & 98.0 \\
\hline & (1.9) & (1.9) & $(4.2)$ & $(4.2)$ & $(2.7)$ & (2.1) \\
\hline \multirow[t]{2}{*}{10.0} & 76.9 & 180 & 93.9 & 112 & 96.1 & 104 \\
\hline & (7.6) & (7.6) & (6.0) & (6.0) & $(4.7)$ & (4.7) \\
\hline
\end{tabular}

Matrix: The spiked solutions were determined with standard solution. which were prepared with matrix matching method.

No matrix: The spiked solutions were determined with standard solutions which were prepared without matrix matching method.

\section{I.S.}

Qualitative and quantitative determinations were performed in the GC-MS full-scan and selective ion monitoring acquisition mode. The retention times of fluorene, anthracene and triphenylene ${ }^{4)}$ were $15 \mathrm{~min}: 21 \mathrm{sec}$, $18 \mathrm{~min}: 25 \mathrm{sec}$ and $28 \mathrm{~min}: 25 \mathrm{sec}$, respectively. Because its retention time was between those of DP and AZO, triphenylene was selected as the I.S.

\section{Matrix effect}

Matrix effects on sensitivity were compensated by use of the internal standard to some extent, but the compensation was insufficient, particularly for DP, OPP and PYRI. One reason for this may be that the retention time of triphenylene (I.S.) was far from the retention times of these fungicides. Although Mastovská et al. ${ }^{5)}$ or González-Rodriguez et $a l .{ }^{6)}$ reported the addition of analyte protectants, we evaluated the conventional matrixmatching method. The addition of matrix solution not containing fungicides to the standard solutions or to the diluted sample solutions effectively equalized the matrix effect. The application of this approach to citrus fruits resulted in stable analytical conditions for GC-MS analysis of real samples. The results of evaluation of the effect of matrix solution are shown in Table 5.

\section{Recoveries}

The recoveries of AZO, FLUDI, IMZ, OPP, PYRI and TBZ spiked in domestic citrus fruits (Satsuma manda$\mathrm{rin}$ ) at the levels of $0.01,0.10,0.50,1.0,5.0$, and $10.0 \mu \mathrm{g} /$
Table 6. Recoveries of fungicides spiked to domestic citrus fruits by GC-MS

\begin{tabular}{cccccccc}
\hline \hline \multirow{2}{*}{$\begin{array}{c}\text { Spiked level } \\
(\mu \mathrm{g} / \mathrm{g})\end{array}$} & \multicolumn{7}{c}{ Recovery $(\%)(\mathrm{RSD}(\%)) n=5$} \\
\cline { 2 - 8 } & AZO & DP & FLUDI & IMZ & OPP & PYRI & TBZ \\
\hline \multirow{2}{*}{0.01} & 87.9 & 78.8 & 88.4 & 98.1 & 104 & 89.0 & 91.6 \\
& $(2.5)$ & $(1.9)$ & $(3.6)$ & $(8.2)$ & $(8.3)$ & $(0.9)$ & $(2.8)$ \\
0.10 & 84.8 & 79.4 & 75.8 & 72.8 & 90.6 & 85.0 & 81.0 \\
& $(3.9)$ & $(4.1)$ & $(4.1)$ & $(9.6)$ & $(7.4)$ & $(4.7)$ & $(5.2)$ \\
0.50 & 102 & 70.8 & 79.4 & 76.4 & 90.0 & 90.3 & 87.5 \\
& $(1.3)$ & $(4.1)$ & $(2.0)$ & $(6.0)$ & $(4.8)$ & $(2.1)$ & $(1.2)$ \\
1.0 & 97.4 & 80.4 & 80.2 & 77.9 & 89.8 & 90.6 & 85.2 \\
& $(1.1)$ & $(1.9)$ & $(2.0)$ & $(3.0)$ & $(4.2)$ & $(2.0)$ & $(1.5)$ \\
5.0 & 94.8 & 75.0 & 79.6 & 79.0 & 91.1 & 91.3 & 83.2 \\
& $(7.0)$ & $(4.1)$ & $(3.5)$ & $(3.5)$ & $(4.6)$ & $(4.9)$ & $(5.7)$ \\
10.0 & 98.8 & 76.9 & 83.5 & 85.4 & 93.9 & 96.1 & 84.8 \\
& $(7.6)$ & $(7.6)$ & $(5.8)$ & $(5.7)$ & $(4.7)$ & $(4.7)$ & $(6.3)$ \\
70.0 & & 78.3 & $(-)$ & $(-)$ & $(-)$ & $(-)$ & $(-)$ \\
& $(-)$ & $(4.7)$ & & & & & \\
\hline
\end{tabular}

$\mathrm{g}$ and the recoveries of DP spiked in domestic citrus fruits (Satsuma mandarin) at the levels of $0.01,0.10$, $0.5,1.0,5.0,10.0$, and $70.0 \mu \mathrm{g} / \mathrm{g}$ are shown in Table 6 . Dilution of the sample solutions was taken into account in the calculations.

The relatively poor results for DP may reflect losses during concentration of the extracted solutions. Motohashi et $a l^{7)}$ reported that the recoveries of DP were excellent when sample solutions were injected into the HPLC directly without concentration.

The recoveries of IMZ were also relatively low (30$40 \%$ ) when the sample solutions were stored at $-30^{\circ} \mathrm{C}$ for three or four months. IMZ may be more labile than the other fungicides, and so analysis should be performed as quickly as possible to minimize degradation of $\mathrm{IMZ}^{8)}$.

The method was validated using Satsuma mandarin samples spiked with fungicides at various concentration levels. Quantitative analysis was performed by matrixmatching methodology. The calibration curves showed good linearity in the range of $0.1-2.0 \mu \mathrm{g} / \mathrm{mL}$ with correlation coefficients larger than 0.999 . The recoveries were in the range of $70-120 \%$ with a relative standard deviation (RSD) of less than 10\%. The quantification limits were fixed at the uniform limit for pesticides in agricultural products to determine particularly AZO and FLU$D I$ in real matrices. The $S / N$ ratios of the seven fungicides were more than $10(20-312)$ at the spiked level of $0.01 \mu \mathrm{g} / \mathrm{g}$. As shown in Fig. 2, no interfering peak was observed on the selective ion monitoring chromatogram for unspiked sample solution.

\section{Analysis of real samples}

The simultaneous determination method was applied to the analysis of fungicides in imported citrus fruits. The analytical data obtained by GC-MS are shown in Table 7.

Both of IMZ and TBZ were detected mainly in imported citrus fruits. AZO, FLUDI and OPP were detected in some samples. DP was not detected in any citrus fruit sample. 

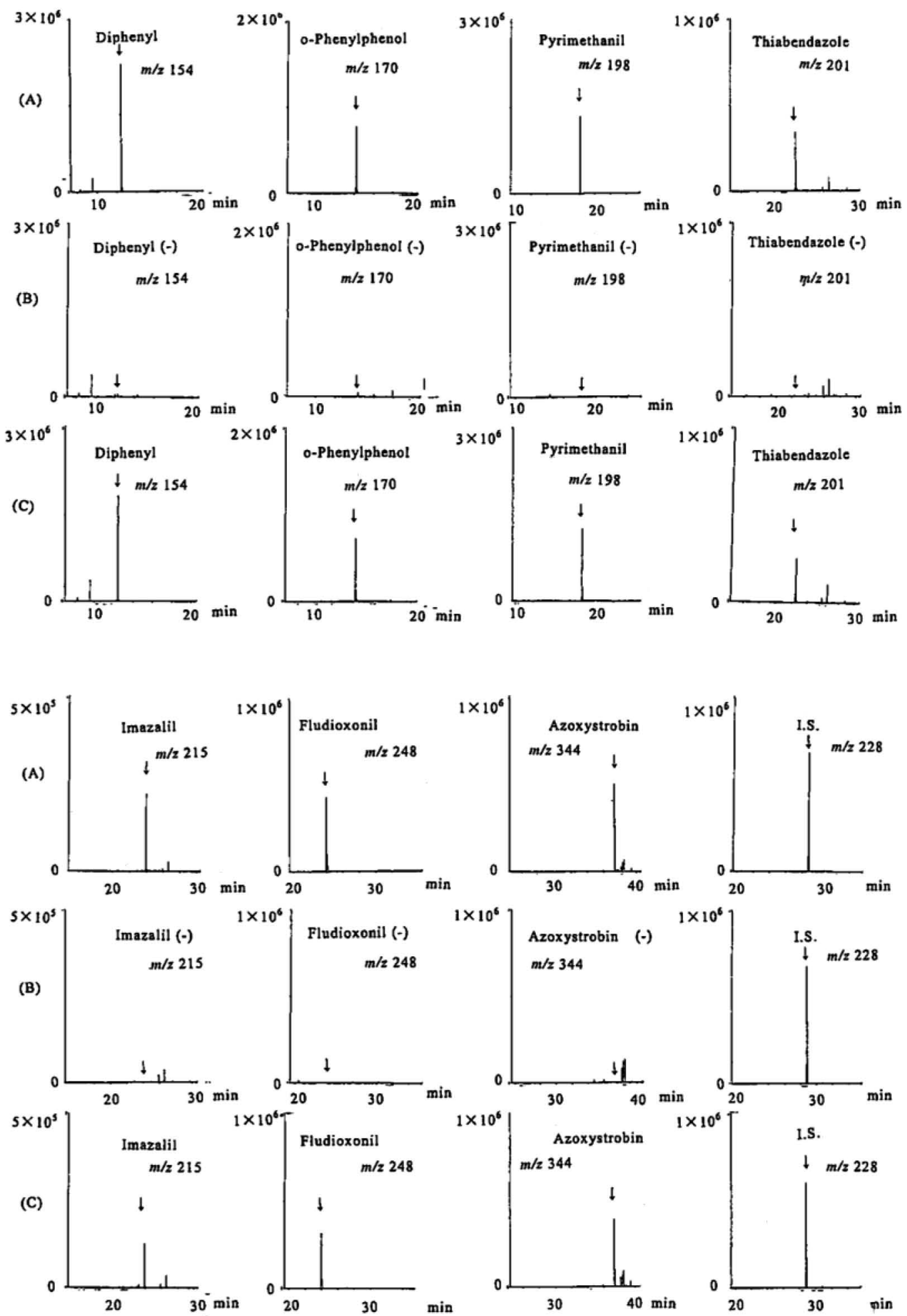

Fig. 2. Typical selective ion monitoring chromatograms of matrix-matched standard solution (1.0 $\mu \mathrm{g} / \mathrm{mL})$ (A), blank Satsuma mandarin sample (B), Satsuma mandarin spiked with diphenyl, o-phenylphenol, pyrimethanil, thiabendazole, imazalil, fludioxonil and azoxystrobin at $0.10 \mu \mathrm{g} / \mathrm{g}$ (C) I.S.: Internal standard

\section{Conclusion}

This paper reports a method for a simultaneous analysis of fungicides in citrus fruits by GC-MS using a matrix-matching method. The best result was obtained us- ing extraction with acetonitrile, washing with phosphate buffer solution ( $\mathrm{pH}$ 7.0) and extraction with an ENVICarb/LC-NH2 as solid-phase cartridge. Triphenylene was added as an internal standard. The proposed method shows high sensitivity with quantification limits of 
Table 7. Examples of determined results of fungicides in citrus fruits

\begin{tabular}{|c|c|c|c|c|c|c|c|c|}
\hline \multirow{2}{*}{$\begin{array}{l}\text { Citrus } \\
\text { fruits }\end{array}$} & & \multicolumn{7}{|c|}{ Fungicides ( $\mu \mathrm{g} / \mathrm{g})$} \\
\hline & & $\mathrm{AZO}$ & DP & FLUDI & IMZ & OPP & PYRI & TBZ \\
\hline Lemon & 1 & 0.01 & N.D. & 0.02 & 1.3 & N.D. & N.D. & 0.11 \\
\hline Lemon & 2 & N.D. & N.D. & 1.3 & 0.11 & N.D. & N.D. & 2.3 \\
\hline Lemon & 3 & N.D. & N.D. & 0.01 & 3.0 & N.D. & N.D. & 0.99 \\
\hline Orange & 1 & N.D. & N.D. & N.D. & 4.4 & N.D. & N.D. & 2.5 \\
\hline Orange & 2 & N.D. & N.D. & N.D. & 1.3 & N.D. & N.D. & 0.95 \\
\hline Orange & 3 & N.D. & N.D. & N.D. & 2.5 & N.D. & N.D. & 2.4 \\
\hline Orange & 4 & N.D. & N.D. & N.D. & 1.0 & N.D. & N.D. & 1.5 \\
\hline Orange & 5 & N.D. & N.D. & N.D. & 1.8 & N.D. & N.D. & 0.90 \\
\hline Grapefruit & 1 & N.D. & N.D. & N.D. & 1.2 & N.D. & N.D. & 2.5 \\
\hline Grapefruit & 2 & N.D. & N.D. & N.D. & 0.69 & N.D. & N.D. & 0.01 \\
\hline Grapefruit & 3 & N.D. & N.D. & N.D. & 0.71 & 0.57 & N.D. & 0.23 \\
\hline Grapefruit & 4 & N.D. & N.D. & N.D. & 1.0 & 0.93 & N.D. & 0.61 \\
\hline
\end{tabular}

$0.01 \mu \mathrm{g} / \mathrm{g}$. It should be suitable for routine analysis of fungicides in commercial lemons, oranges and grapefruits.

\section{References}

1) Inoue, K., Tsurumi, T., Ishii, H., Park, P., Ikeda, K. Cytological evaluation of the effect of azoxystrobin and alternative oxidase inhibitors in Botrytis cinerea. FEMS Microbial Lett., 326(1), 83-90 (2012).

2) Vorstermans, B., Creemers, P. Screening preharvest/ postharvest strategies to prevent fruit rot decay. Commun. Agric. Appl. Biol. Sci., 72, 909-915 (2007).

3) Yoshioka, N., Hayashi, S., Inada, T. Rapid determination of seven fungicides in citrus fruits. Food Hyg. Saf. Sci., 56, 228-232 (2015).

4) Nakagawa, R. Development of a simple screening method for residual pesticides in crops using acetonitrilewater extraction and solid phase minicolumn cleanup. Fukuoka-ken Hoken Kankyou Kenkyuujo Nenpou, 28, 83-88 (2001).

5) Mastovská, K., Lehotay, S. J., Anastassiades, M. Combination of analyte protectants to overcome matrix effects in routine $\mathrm{GC}$ analysis of pesticide residues in food matrices. Anal. Chem., 77, 8129-8137 (2005).

6) González-Rodriguez, R. M., Cancho-Grande, B., SimalGándara, J. Multiresidue determination of 11 new fungicides in grapes and wines by liquid-liquid extraction/ clean-up and programmable temperature vaporization injection with analyte protectants/gas chromatography/ ion trap mass spectrometry. J. Chromatogr. A, 1216, 6033-6042 (2009).

7) Motohashi, N., Nagashima, H., Meyer, R. High-performance liquid chromatography of fungicides in citrus fruits. J. Liq. Chromatogr., 14, 3591-3602 (1991).

8) Besil, N., Pérez-Parada, A., Cesio, V., Varela, P., Rivas, F., Heinzen, H. Degradation of imazalil, ortho-phenylphenol and pyrimethanil in Clementine mandarins under conventional postharvest industrial conditions at $4^{\circ} \mathrm{C}$. Food Chem., 194, 1132-1137 (2016). 